\title{
DESEMPENHO DE CULTIVARES DE JILÓ EM CASA DE VEGETAÇÃO $\left({ }^{1}\right)$
}

\author{
MARIA DO CARMO DE SALVO SOARES NOVO $\left({ }^{2 *}\right)$; PAULO ESPÍNDOLA TRANI $\left({ }^{3}\right)$; \\ GLAUCO DE SOUZA ROLIM $\left({ }^{2}\right)$; LUÍS CARLOS BERNACCI $\left({ }^{4}\right)$
}

\begin{abstract}
RESUMO
O experimento foi instalado em vasos plásticos, em casa de vegetação em Campinas (SP). Duas cultivares comerciais de jiló - Solanum gilo Raddi - (Comprido Verde-Claro e Esmeralda) e duas introduzidas pelo IAC (Bernacci e Cardoso) foram avaliadas em relação ao desenvolvimento vegetativo e à produtividade. As mudas foram produzidas em bandejas de poliestireno com 128 células e, o transplantio foi realizado aos 40 dias após a semeadura quando estavam no estádio de quatro a cinco folhas definitivas. Aos 30, 60 e 90 dias após o transplantio, avaliaram-se o número de folhas, a altura, a área foliar e as biomassas fresca e seca da parte aérea. Após o início da frutificação, semanalmente, foram colhidos os frutos e avaliaram-se diâmetros, comprimentos e biomassa fresca. As cultivares de jiló Esmeralda e Comprido Verde-Claro produziram frutos mais precoces em relação às cultivares Bernacci e Cardoso. Estas últimas produziram frutos por período mais prolongado. O jiló 'Cardoso' foi o mais produtivo quanto ao número total de frutos e à biomassa fresca total. As cultivares Bernacci e Cardoso da coleção do IAC, com potencial para o melhoramento genético, podem ainda ser utilizadas no sistema de produção de subsistência ou na agricultura familiar que são os sistemas tradicionais de cultivo de jiló.
\end{abstract}

Palavras-chave: Solanaceae, hortaliça, crescimento de plantas, produção.

\section{ABSTRACT \\ PERFORMANCE OF JILO CULTIVARS IN GLASSHOUSE CONDITIONS}

The experiment was carried out in plastic pots in a glasshouse, in Campinas, São Paulo State, Brazil. Two commercial Solanum gilo Raddi cultivars (Comprido Verde-Claro and Esmeralda) and two introduced by IAC (Bernacci and Cardoso) were evaluated as to their vegetative development and fruit yield. The transplantings were produced in polystyrene trays with 128 cells and the transplant was done 40 days after sowing when the plants had four or five true leaves. The number of leaves, the height, leaf area and the fresh and dry shoot weight were evaluated 30,60 and 90 days after transplant. Weekly, after fruiting began, the fruits were picked and their diameter, length and fresh biomass were measured. 'Esmeralda' and 'Comprido Verde-Claro' showed premature fruit production when compared to Bernacci and Cardoso cultivars. The latter cultivars yielded fruits for longer period of time. Cardoso cultivar produced a bigger number and a larger total fresh fruit biomass than the other genotypes. Bernacci and Cardoso cultivars of IAC germoplasm collection showed to be genotypes with potential to be used in genetic improvement, in familiar agriculture and in the system of support production and they are the traditional ways of jilo cultivation.

Key words: Solanaceae, vegetable, plant growth, yield.

(1) Recebido para publicação em 27 de fevereiro de 2007 e aceito em 14 de abril de 2008.

$\left({ }^{2}\right)$ Centro de Ecofisiologia e Biofísica, Instituto Agronômico (IAC), Caixa Postal 28, 13001-970 Campinas (SP). E-mail: jpsnovo@iac.sp.gov.br $\left(^{*}\right)$ Autora correspondente; grolim@iac.sp.gov.br

$\left({ }^{3}\right)$ Centro de Horticultura, IAC. E-mail: petrani@iac.sp.gov.br

( $\left.{ }^{4}\right)$ Núcleo do Jardim Botânico, IAC. E-mail: bernacci@iac.sp.gov.br 


\section{INTRODUÇÃO}

O jiloeiro (Solanum gilo Raddi) é uma planta pertencente à família das Solanáceas com origem provável na África, e introduzido no Brasil pelos escravos. Nos dias de hoje, diversas cultivares de jiló são ainda bastante cultivadas na Nigéria, sendo empregadas na medicina caseira. Segundo ODETOLA et al. (2004), plantas de jiló contêm flavonóides, alcalóides e esteróides e seus frutos têm propriedades antioxidantes com habilidade de abaixar o nível de colesterol. Os frutos contêm aproximadamente 92,5\% de água, $1 \%$ de proteína, $0,3 \%$ de gordura e $6 \%$ de carboidrato (ODETOLA et al., 2004).

Segundo Filgueira (2003), o jiló é uma hortaliça de grande aceitação principalmente na Região Sudeste do Brasil. Os frutos são de formas diversas, de redondo a ovóide, com casca fina e coloração variada (NAGAI, 1998). MorgAdo e Dias (1992) relataram que, em relação ao formato dos frutos, $61 \%$ são redondos, $20 \%$ achatados, 9,5\% alongados e 9,5\% ovais. A maioria dos frutos observados no mercado é de cor verde-clara ou escura quando imaturos, sendo apreciados por seu sabor amargo característico e suas propriedades digestivas (CARVALHO e RibeIRo, 2002). Sua colheita, transporte e comercialização ocorrem quando os frutos ainda estão imaturos (NERES et al., 2004).

No Brasil, há no mercado, poucas cultivares disponíveis e todas são nacionais (Morgado e Dias, 1992). No mercado brasileiro de sementes verificamse dois tipos básicos de jiló: 'Comprido Verde-Claro' e 'Morro Grande', sendo o último de sabor mais amargo (WorldCrops, 2005). Há diferença no comportamento dos consumidores de jiló em função de região. No Rio de Janeiro, o mercado consumidor prefere frutos de coloração verde-clara e formato alongado, enquanto em São Paulo, a maior aceitação é por exemplares arredondados e verde-escuros (CARVAlHo e Ribeiro, 2002). Nos Estados Unidos, ambas as cultivares têm sido cultivadas e comercializadas com sucesso (MANGan et al., sd).

Embora o jiló seja uma planta pouco estudada, sabe-se de suas exigências por temperaturas elevadas, água e baixa tolerância ao frio o que o caracteriza como cultura tipicamente tropical (PICANÇO et al., 1997). Minami e Gonçalves (1986), considerando que o jiló é uma planta muito exigente em calor, indicam o período de agosto a fevereiro para plantio desta hortaliça no Estado de São Paulo. Porém, Torres et al. (2003) consideraram que o jiló pode ser plantado o ano inteiro em localidades de inverno suave. NAGAI (1998) relata que o jiloeiro pode ser cultivado o ano todo no litoral paulista e de agosto a março no interior do Estado. Segundo Filgueira (2003), o jiloeiro é muito exigente em temperatura e embora não mencionando as faixas ideais e críticas para esta hortaliça, relata que sob baixas temperaturas durante o inverno, pode ocorrer queda de flores e frutos novos. A colheita do jiló inicia-se 80 a 100 dias após a semeadura, prolongando-se por mais de cem dias.

Na região metropolitana de Campinas, duas cultivares são comercializadas: Esmeralda e Comprido Verde-Claro (daqui para frente citada como VerdeClaro). A cultivar Esmeralda (híbrido) possui frutos arredondados, de cor verde médio a escuro e brilhante e 'Verde-Claro', de frutos oblongos a alongados, verde-claros. Em 1997, foram introduzidas no Instituto Agronômico, em Campinas (SP), duas cultivares de jiló: Cardoso e Bernacci. Essas cultivares diferenciamse das existentes no mercado pelas folhas recortadas, flores grandes e roxas e por frutos grandes e achatados, similares aos do tomate caqui. Os frutos da cultivar Bernacci são verde-escuros e os da 'Cardoso', brancos.

O presente trabalho teve como objetivo avaliar o desempenho das cultivares de jiló Esmeralda, VerdeClaro, Cardoso e Bernacci cultivadas em casa de vegetação, quanto ao seu desenvolvimento vegetativo e à produção de frutos.

\section{MATERIAL E MÉTODOS}

O experimento foi instalado em vasos plásticos, em casa de vegetação do Centro de Ecofisiologia e Biofísica, do Instituto Agronômico (IAC), em Campinas (SP), em 17/3/04. Os vasos com formato trapezoidal (diâmetro maior de 25,6 cm, diâmetro menor de $16,2 \mathrm{~cm}$ e altura de $22,5 \mathrm{~cm}$ ) foram preenchidos com Latossolo Vermelho peneirado (malha de $4 \mathrm{~mm}$ ), corrigido e adubado, de acordo com o recomendado por TRANI et al. (1996). Em cada vaso foi colocado $8 \mathrm{~L}$ de terra. O resultado da análise química de amostra composta coletada nos vasos do experimento foi: matéria orgânica: $21 \mathrm{~g} \mathrm{dm}^{-3} ; \mathrm{pH}$ em $\mathrm{CaCl}_{2:}$ 6,1; P resina: $6 \mathrm{mmol}_{\mathrm{C}} \mathrm{dm}^{-3} ; \mathrm{K}: 0,8 \mathrm{mmol}_{\mathrm{C}} \mathrm{dm}^{-3}$; Ca: $23 \mathrm{mmol}_{\mathrm{C}} \mathrm{dm}^{-3} ; \mathrm{Mg}: 9 \mathrm{mmol}_{\mathrm{c}} \mathrm{dm}^{-3} ; \mathrm{H}+\mathrm{Al}: 15 \mathrm{mmol}_{\mathrm{c}}$ $\mathrm{dm}^{-3}$; SB: $23 \mathrm{mmol}_{\mathrm{c}} \mathrm{dm}^{-3}$; CTC: $48 \mathrm{mmol}_{\mathrm{C}} \mathrm{dm}^{-3}$; V: 69\%; Fe: $8 \mathrm{mg} \mathrm{dm}^{-3}$; Mn: 1,6 $\mathrm{mg} \mathrm{dm}^{-3} ; \mathrm{Cu}: 1,1 \mathrm{mg} \mathrm{dm}^{-3} ; \mathrm{Zn}$ : $0,5 \mathrm{mg} \mathrm{dm}^{-3}$ e B: $0,13 \mathrm{mg} \mathrm{dm}^{-3}$.

Duas cultivares comerciais (Verde-Claro e Esmeralda) e duas introduzidas pelo IAC (Bernacci e Cardoso) foram avaliadas. As mudas de jiló foram produzidas em bandejas de poliestireno com 128 células, preenchidas com substrato Plantmax HT, sendo semeadas duas sementes por célula. $\mathrm{O}$ desbaste foi realizado cinco dias após a emergência das plântulas, sendo mantida uma planta por célula. As 
mudas foram transplantadas aos 40 dias após a semeadura $(27 / 4 / 04)$ quando estavam no estádio de quatro a cinco folhas definitivas. Quinze dias antes do transplante das mudas foi aplicado ao solo o equivalente a $600 \mathrm{~kg} \mathrm{ha}^{-1}$ de $\mathrm{P}_{2} \mathrm{O}_{5}$ (na forma de superfosfato simples), $180 \mathrm{~kg} \mathrm{ha}^{-1} \mathrm{de}_{2} \mathrm{O}$ (na forma de sulfato de potássio) e $1 \mathrm{~kg} \mathrm{ha}^{-1}$ de $\mathrm{B}$ (na forma de bórax). As coberturas com nitrogênio e potássio foram parceladas a cada sete dias nas doses totais recomendadas por TRANI et al. (1996).

Após o transplantio, foi realizada uma irrigação leve sendo colocada na superfície dos vasos uma camada de um centímetro de vermiculita. A seguir, os vasos foram irrigados até a percolação (da solução do solo). Foram empregados 36 vasos por cultivar sendo 27 usados nas avaliações de crescimento e nove para produção. De acordo com o Instituto Mineiro de Agropecuária (sd), para evitar cruzamento deve ser observado isolamento mínimo de $400 \mathrm{~m}$ entre campos com diferentes cultivares de jiló. Por esse motivo, para fins de produção de sementes, cada material foi mantido em um compartimento da casa de vegetação, separados entre si por paredes e portas de vidro mantidas fechadas durante todo o experimento. A cada 21 dias, pulverizou-se com Nitrophoska A na dose de $1 \mathrm{cc} \mathrm{L} \mathrm{L}^{-1}$ de água. Também foram realizadas pulverizações fitossanitárias, conforme a necessidade da cultura. As plantas foram estaqueadas com bambu para mantê-las eretas e evitar quebra das hastes.

Aos 30, 60 e 90 dias após o transplantio, avaliou-se o número de folhas, a altura, a área foliar e as biomassas fresca e seca da parte aérea. As folhas foram mantidas sob refrigeração por, no máximo, duas horas até a determinação da área foliar. Para determinação da biomassa seca, as estruturas da parte aérea foram secas em estufa sob ventilação forçada a $65-70{ }^{\circ} \mathrm{C}$, até atingir massa constante. Após o início da frutificação, semanalmente, foram colhidos os frutos e avaliaram-se o diâmetro, o comprimento e a biomassa fresca por planta. Para as medições do diâmetro e do comprimento dos frutos foi usado o método descrito por Morgado e Dias (1992). O diâmetro foi medido no comprimento médio do fruto. O comprimento do fruto foi medido do ápice do pedúnculo até o ponto central da parte distal.

Para avaliação dos dados, foi efetuada primeiramente uma análise multivariada com "cluster" aglomerativo, "Agglomerative Hierarchical Clustering (AHC)", com método de otimização das distâncias euclidianas proposta por WARD (1963), com todos os valores das características avaliadas no experimento. Essa análise possibilita uma comparação geral do desenvolvimento vegetativo e da produtividade entre as cultivares.
Para número de folhas, altura média das plantas, área foliar e biomassas fresca e seca da parte aérea, a análise de variância foi realizada de acordo com o método para parcelas subdivididas (STEel e TORRIE, 1980), sendo considerada como parcelas as cultivares e como subparcelas, as épocas de avaliação (30, 60 e 90 dias após o transplantio). A comparação das médias entre cultivares foi realizada utilizandose a análise de intervalo de confiança a $5 \%$ de probabilidade e regressão polinomial para os efeitos de época de avaliação. Os dados de número médio de folhas e de frutos foram transformados em $\sqrt{x}$ para análise estatística. Para analisar número médio, produção, comprimento e diâmetro dos frutos também foi usada a análise de intervalo de confiança. Foi analisado o efeito do tempo na produção dos frutos, mas estes não foram significativos, motivo pelo qual não foram discutidos no trabalho.

\section{RESULTADOS E DISCUSSÃO}

De forma geral, a análise de "cluster" demonstra a grande diferença no desempenho vegetativo e produtivo da cultivar Cardoso em relação às demais (Figura 1). Observa-se também nas cultivares Esmeralda e Verde-Claro as menores distâncias euclidianas, evidenciando a grande semelhança em relação às características avaliadas no experimento (altura final das plantas, número final de folhas, biomassa fresca e seca da parte aérea, área foliar e características dos frutos: diâmetro, comprimento, número e produção de frutos).

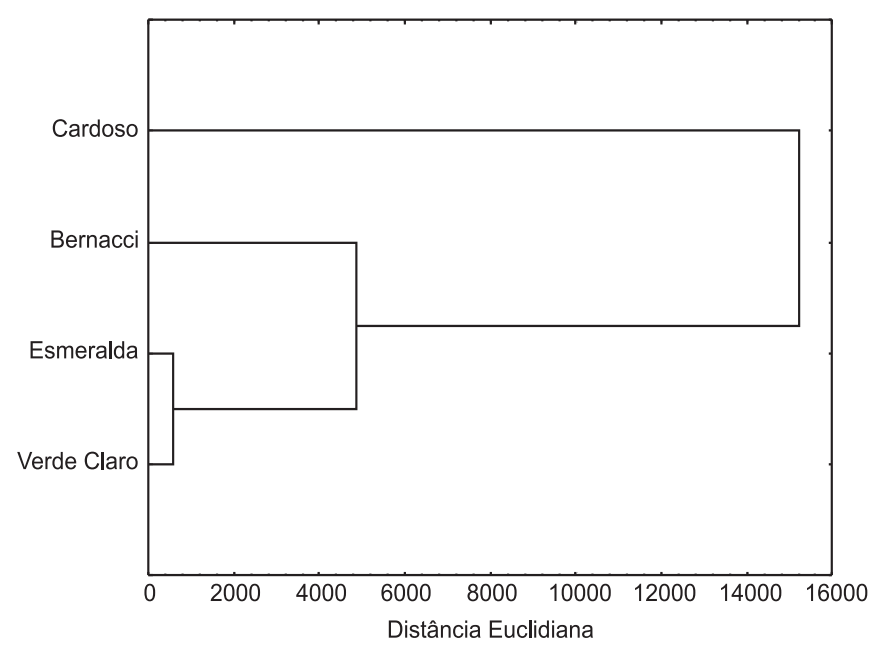

Figura 1. Dendrograma resultante de análise de "cluster", utilizando os valores de todas as características avaliadas no experimento (altura final das plantas, número final de folhas, biomassa fresca e seca da parte aérea, área foliar e características dos frutos: diâmetro, comprimento, número e produção de frutos) das cultivares Cardoso, Bernacci, Esmeralda e Verde-Claro. 
Tabela 1. Diferenças entre as cultivares Cardoso, Bernacci, Esmeralda e Verde-Claro para alturas médias de plantas e número médio de folhas nas avaliações realizadas em abril, maio e julho, aos 30, 60 e 90 dias após o transplantio. Campinas, 2004/2005

\begin{tabular}{lccccc}
\hline \multirow{2}{*}{ Cultivares } & \multicolumn{4}{c}{ Altura média de plantas $(\mathrm{cm})$} \\
\cline { 2 - 6 } & 30 dias & 60 dias & 90 dias & Equação de regressão e coeficientes de determinação \\
\hline Cardoso & $13,3 \mathrm{c}$ & $14,9 \mathrm{c}$ & $36,6 \mathrm{c}$ & $\mathrm{Y}=-1,79+0,390 \mathrm{x}$ & $\mathrm{R}^{2}=80,19 \%$ \\
Bernacci & $15,6 \mathrm{bc}$ & $21,5 \mathrm{c}$ & $30,8 \mathrm{c}$ & $\mathrm{Y}=7,50+0,251 \mathrm{x}$ & $\mathrm{R}^{2}=98,37 \%$ \\
Esmeralda & $29,4 \mathrm{a}$ & $67,8 \mathrm{a}$ & $89,9 \mathrm{~b}$ & $\mathrm{Y}=1,83+1,0083 \mathrm{x}$ & $\mathrm{R}^{2}=97,65 \%$ \\
Verde Claro & $23,1 \mathrm{ab}$ & $47,4 \mathrm{~b}$ & $107,5 \mathrm{a}$ & $\mathrm{Y}=-25,04+1,406 \mathrm{x}$ & $\mathrm{R}^{2}=94,32 \%$ \\
\hline Número médio de folhas $\left(^{1}\right)$ & & & & $\mathrm{R}^{2}=100,00 \%$ \\
Cardoso & $8,1 \mathrm{c}$ & $7,4 \mathrm{~b}$ & $12,8 \mathrm{~b}$ & $\mathrm{Y}=3,94-0,053 \mathrm{x}+0,0005 \mathrm{x}^{2}$ & $\mathrm{R}^{2}=100,00 \%$ \\
Bernacci & $13,8 \mathrm{ab}$ & $18,8 \mathrm{a}$ & $16,8 \mathrm{~b}$ & $\mathrm{Y}=2,24+, 063 \mathrm{x}-0,00048 \mathrm{x}^{2}$ & $\mathrm{R}^{2}=91,40 \%$ \\
Esmeralda & $14,9 \mathrm{a}$ & $19,9 \mathrm{a}$ & $41,2 \mathrm{a}$ & $\mathrm{Y}=2,36+0,0426 \mathrm{x}$ & $\mathrm{R}^{2}=87,53 \%$ \\
Verde Claro & $10,3 \mathrm{bc}$ & $10,7 \mathrm{~b}$ & $36,8 \mathrm{a}$ & $\mathrm{Y}=1,52+0,0465 \mathrm{x}$ & \\
\hline
\end{tabular}

Médias seguidas por letras iguais, na coluna, não diferem entre si pela análise de intervalos de confiança a $5 \%$ de probabilidade.

$\left({ }^{1}\right)$ Dados transformados em $\sqrt{x}$ para análise estatística e apresentação das médias dos dados originais. As equações e os coeficientes de determinação referem-se aos dados transformados.

Observou-se que para as quatro cultivares, as alturas médias das plantas aumentaram linearmente com o tempo (Tabela 1). Aos 30, 60 e 90 dias após o transplantio, foi observado que a cultivar Esmeralda apresentou maior altura que 'Cardoso' e 'Bernacci'. Aos 90 dias, as maiores alturas média das plantas foram observadas nas cultivares Verde-Claro e Esmeralda. De modo geral, as cultivares Cardoso e Bernacci foram sempre menores em todo o período de desenvolvimento, em relação à 'Esmeralda' e 'Verde-Claro'.

O número de folhas das cultivares Esmeralda e Verde-Claro aumentou linearmente em função do tempo. Estimou-se que o número médio de folhas da cultivar Cardoso foi reduzido até 53 dias e o da 'Bernacci' aumentou até 66 dias. As plantas da cultivar Esmeralda sempre estiveram no grupo de maior número de folhas (Tabela 1). Em todas as épocas de avaliação, de modo geral, o jiló 'Cardoso' esteve no grupo de menor número de folhas, constatandose que esta cultivar tem desenvolvimento vegetativo mais lento.

Para as quatro cultivares, houve aumento linear nas biomassas fresca e seca da parte aérea e na área foliar em função do tempo (Tabela 2). Aos 30 dias, as biomassas fresca e seca da parte aérea da cultivar Esmeralda foram superiores a da 'Cardoso'. Aos 60 dias, observou-se que as biomassas fresca e seca da parte aérea nas cultivares Esmeralda e Bernacci foram maiores que da 'Cardoso'. Aos 90 dias, observou-se na cultivar Bernacci biomassa fresca da parte aérea menor que a dos outros materiais. Entretanto, nessa mesma época de avaliação, as maiores biomassas secas foram observadas nas cultivares Esmeralda e Verde-Claro e menores em 'Cardoso' e 'Bernacci'.

No início do crescimento (30 dias), a área foliar da cultivar Esmeralda foi superior à das outras cultivares. Aos 60 dias, a área foliar de 'Esmeralda' e 'Bernacci' eram superiores à da 'Cardoso'. Aos 90 dias, a área foliar da cultivar Verde-Claro era superior à da 'Bernacci', mas não diferiu das demais.

Houve diferença no tempo necessário para que as cultivares iniciassem seus florescimentos. 'Esmeralda' foi a mais precoce iniciando seu florescimento um mês após o transplantio com $62 \%$ das plantas com flores; aos quarenta e oito dias após o transplantio, em todas as plantas havia flores e em $15 \%$ delas, frutos. As cultivares Verde-Claro e Cardoso iniciaram seu florescimento aos 40 dias após o transplantio, mas aos 48 dias em nenhuma era observada frutificação. O florescimento da cultivar Bernacci ocorreu aos 48 dias após o transplantio e também teve a frutificação retardada. No início do florescimento, observou-se queda na temperatura o que ocasionou abortamento das flores em todas as cultivares e conseqüente atraso no início da frutificação. O abortamento das flores foi mais pronunciado nas cultivares Cardoso e Bernacci, mais sensíveis ao frio em relação às demais cultivares. 
Tabela 2. Diferenças nas biomassas fresca e seca da parte aérea e na área foliar das cultivares Cardoso, Bernacci, Esmeralda e Verde-Claro nas amostragens realizadas em abril, maio e julho aos 30, 60 e 90 dias após o transplantio. Campinas, 2004/2005

\begin{tabular}{|c|c|c|c|c|c|}
\hline \multirow{2}{*}{ Cultivares } & \multicolumn{5}{|c|}{ Biomassa fresca da parte aérea $\left(\mathrm{g}_{\text {planta }}{ }^{-1}\right)$} \\
\hline & 30 dias & 60 dias & 90 dias & \multicolumn{2}{|c|}{ Equação de regressão e coeficientes de determinação } \\
\hline Cardoso & $20,3 \mathrm{~b}$ & $33,9 \mathrm{c}$ & $103,4 \mathrm{ab}$ & $Y=-30,51+1,384 x$ & $\mathrm{R}^{2}=86,91 \%$ \\
\hline Bernacci & $25,7 \mathrm{ab}$ & $79,7 \mathrm{ab}$ & $81,7 \mathrm{~b}$ & $Y=6,37+0,933 x$ & $\mathrm{R}^{2}=77,68 \%$ \\
\hline Esmeralda & 33,74 a & $78,2 \mathrm{a}$ & 129,2 a & $Y=15,03+1,59 x$ & $\mathrm{R}^{2}=99,85 \%$ \\
\hline Verde-Claro & $21,6 \mathrm{~b}$ & $47,7 \mathrm{bc}$ & $137,8 \mathrm{ab}$ & $Y=-47,07+1,935 x$ & $\mathrm{R}^{2}=90,78 \%$ \\
\hline C.V. (a) & $15,18 \%$ & - & - & - & - \\
\hline C.V. (b) & $32,56 \%$ & - & - & - & - \\
\hline \multicolumn{6}{|c|}{ Biomassa seca da parte aérea (g planta ${ }^{-1}$ ) } \\
\hline Cardoso & $2,9 \mathrm{~b}$ & $5,0 \mathrm{c}$ & $17,1 \mathrm{~b}$ & $Y=-5,954+0,238 x$ & $\mathrm{R}^{2}=85,84 \%$ \\
\hline Bernacci & $3,4 \mathrm{ab}$ & $12,2 \mathrm{a}$ & $16,6 \mathrm{~b}$ & $Y=-2,464+0,220 x$ & $R^{2}=96,29 \%$ \\
\hline Esmeralda & 5,2 a & $14,2 \mathrm{a}$ & $26,4 \mathrm{a}$ & $Y=-5,954+0,354 x$ & $\mathrm{R}^{2}=98,83 \%$ \\
\hline Verde-Claro & $3,7 \mathrm{ab}$ & $8,4 \mathrm{~b}$ & $26,3 \mathrm{a}$ & $Y=-9,878+0,377 x$ & $\mathrm{R}^{2}=89,76 \%$ \\
\hline C.V. (a) & $14,69 \%$ & - & - & - & - \\
\hline C.V. (b) & $35,00 \%$ & - & - & - & - \\
\hline \multicolumn{6}{|c|}{ Área foliar $\left(\mathrm{cm}^{2}\right.$ planta $\left.^{-1}\right)$} \\
\hline Cardoso & $451,73 \mathrm{~b}$ & $713,75 \mathrm{c}$ & $1974,25 \mathrm{~b}$ & $Y=-475,95+25,375 x$ & $\mathrm{R}^{2}=87,46 \%$ \\
\hline Bernacci & $514,89 \mathrm{~b}$ & $1425,45 \mathrm{ab}$ & $1500,40 \mathrm{c}$ & $Y=161,40+16,43 x$ & $\mathrm{R}^{2}=80,67 \%$ \\
\hline Esmeralda & 903,86 a & $1538,23 \mathrm{a}$ & 2467,42 a & $Y=72,95+26,06 x$ & $\mathrm{R}^{2}=98,83 \%$ \\
\hline Verde-Claro & $560,08 \mathrm{~b}$ & $1091,73 \mathrm{~b}$ & $2622,40 \mathrm{ab}$ & $Y=-637,59+34,37 x$ & $\mathrm{R}^{2}=92,75 \%$ \\
\hline C.V. (a) & $10,92 \%$ & - & - & - & - \\
\hline C.V. (b) & $29,64 \%$ & - & - & - & - \\
\hline
\end{tabular}

Médias seguidas por letras iguais, na coluna, não diferem entre si pela análise de intervalos de confiança a 5\% de probabilidade.

Filgueira (2003) relata que é possível um segundo período de colheita de jiló, na primavera seguinte, após as plantas serem afetadas pelo frio de inverno, o que também foi constatado neste experimento para todas as cultivares. As cultivares Cardoso e Bernacci floresceram e frutificaram durante o segundo inverno a que sobreviveram. Cabe ressaltar que as cultivares Esmeralda e Verde-Claro iniciaram suas produções a partir de maio, prolongando até novembro de 2004, sendo necessário, no início de dezembro, podá-las, mas as plantas não se recuperaram adequadamente. Entretanto, 'Cardoso' e 'Bernacci' produziram regularmente apenas a partir de agosto de 2004 e estendendo-se até agosto de 2005.

As características morfológicas dos frutos são fatores importantes na comercialização e devem estar dentro dos padrões exigidos pelo mercado atacadista e consumidor (Torres et al., 2003). Nesse experimento, as características dos frutos como diâmetro e comprimento foram de grande variabilidade, sendo o mesmo observado por Morgado e Dias (1992) na avaliação de 44 genótipos de jiló.

Não houve diferença estatística nos valores de diâmetro médio dos frutos nas épocas de coleta entre as quatro cultivares estudadas (Figura 2). Entretanto, houve grande variação no diâmetro dos frutos dentro de cada cultivar. O diâmetro médio dos frutos variou de 3,9 a $6,6 \mathrm{~cm} ; 2,9$ a $5,9 \mathrm{~cm}$ e 2,4 a $4,2 \mathrm{~cm}$, respectivamente, nas cultivares Cardoso, Bernacci e Esmeralda. Na 'Verde-Claro', a variação no diâmetro foi menor (de 2,5 a 2,8 cm). Os dados obtidos para o jiló 'Verde-Claro' são similares aos obtidos por TORRES et al. (2003), que relataram que o diâmetro médio de frutos da cultivar Tinguá, com indivíduos morfologicamente semelhantes, variou de 2,7 a 2,9 cm. Os frutos das cultivares Cardoso e Bernacci, em quase todas as épocas de coleta, tiveram frutos com maior diâmetro que 'Esmeralda' e'Verde-Claro'. Comparandose as cultivares entre si (Tabela 3), verificou-se em 'Verde-Claro' e 'Esmeralda' frutos com o menor diâmetro e em 'Cardoso' e 'Bernacci', os maiores. 


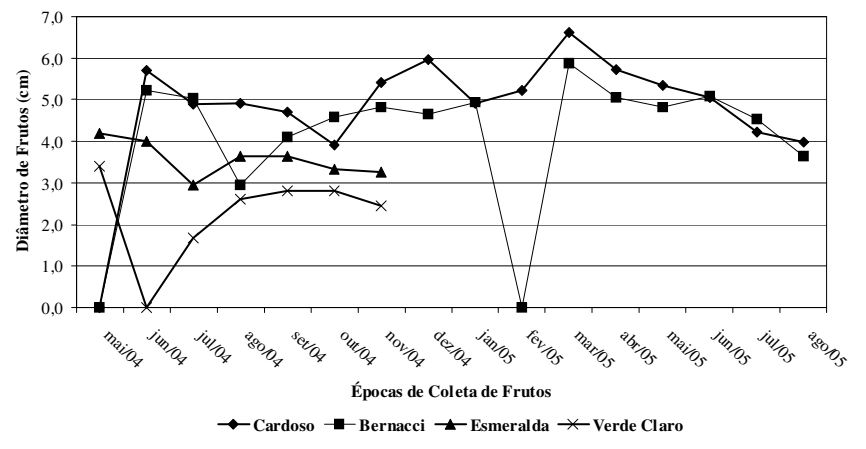

Figura 2. Efeito das diferentes épocas de coleta no diâmetro médio dos frutos nas cultivares Cardoso, Bernacci, Esmeralda e Verde-Claro. Campinas, 2004/2005.
O efeito das diversas épocas de coleta de frutos para o comprimento médio dos frutos foi pequeno (Figura 3), mas houve grande variação dentro de cada cultivar. Em 'Cardoso' observaram-se frutos com comprimento médio variando de 3,4 a 5,2 cm; em Bernacci, variou de 2,3 a 5,7 cm; em Esmeralda, de 3,5 a $4,9 \mathrm{~cm}$ e em Verde-Claro, de 3,5 a $7,4 \mathrm{~cm}$. Para a cultivar Tinguá, TorRes et al. (2003) observaram que o comprimento médio do fruto variou de 5,8 a 6,0 cm. Houve menor variação no experimento desses autores, pois seus frutos foram colhidos em uma única época. Comparando-se as cultivares entre si, verificou-se que não houve diferença entre cultivares para comprimento médio dos frutos (Tabela 3).

Tabela 3. Diferença entre cultivares para diâmetro, comprimento, número e produção total de frutos (nove plantas). Campinas, SP, 2004/2005

\begin{tabular}{lcccc}
\hline Cultivares & Diâmetro de frutos & Comprimento de frutos & Número de frutos $\left(^{1}\right)$ & Produção de frutos \\
\cline { 2 - 3 } & \multicolumn{2}{c}{$\mathrm{cm}$} & $\mathrm{n}^{\circ}$ planta $^{-1}$ & $\mathrm{~g} \mathrm{planta}^{-1}$ \\
Cardoso & $5,1 \mathrm{a}$ & $4,2 \mathrm{a}$ & $39 \mathrm{a}$ & $2005,8 \mathrm{a}$ \\
Bernacci & $4,7 \mathrm{a}$ & $4,0 \mathrm{a}$ & $27 \mathrm{~b}$ & $1060,9 \mathrm{~b}$ \\
Esmeralda & $3,6 \mathrm{~b}$ & $4,1 \mathrm{a}$ & $26 \mathrm{~b}$ & $659,3 \mathrm{c}$ \\
Verde-Claro & $2,6 \mathrm{~b}$ & $5,5 \mathrm{a}$ & $31 \mathrm{~b}$ & $621,4 \mathrm{c}$ \\
CV $(\%)$ & 5 & 8 & 5 & 10 \\
\hline
\end{tabular}

$\left({ }^{1}\right)$ Dados transformados em $\sqrt{x}$ para análise estatística, mas são apresentados os dados originais.

Médias seguidas por letras iguais, na coluna, não diferem entre si pela análise de intervalos de confiança a $5 \%$ de probabilidade.

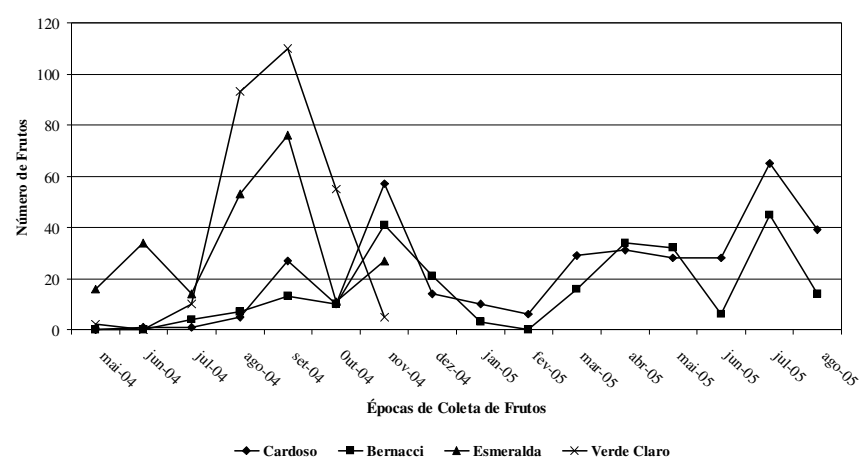

Figura 3. Efeito das diferentes épocas de avaliação no comprimento médio dos frutos das cultivares Cardoso, Bernacci, Esmeralda e Verde-Claro. Campinas, 2004/2005.

Não houve diferença entre cultivares dentro de cada época de coleta quanto ao número de frutos. Entretanto, observa-se que nas primeiras avaliações havia maior número de frutos de 'Esmeralda' e 'Verde-Claro' que de 'Cardoso' e 'Bernacci' (Figura 4). Nas cultivares Esmeralda e Verde-Claro os maiores números de frutos ocorreram em setembro de 2004 (Figura 4). Em 'Bernacci' e 'Cardoso' ocorreu o maior número de frutos em julho de 2005, sugerindo maior necessidade de nutrientes que 'Esmeralda' e 'VerdeClaro' para produzir. Comparando-se as cultivares entre si, foi observado na 'Cardoso' maior número de frutos, não sendo verificado diferença entre as outras três cultivares avaliadas (Tabela 3). Devido à sazonalidade semelhante no número médio de frutos (Figura 4), em todas as cultivares nas diferentes épocas de colheita, (por exemplo, o aumento em setembro e a diminuição em janeiro e fevereiro) pode-se inferir que os elementos climáticos como temperatura do ar e radiação solar têm efeito direto na produtividade.

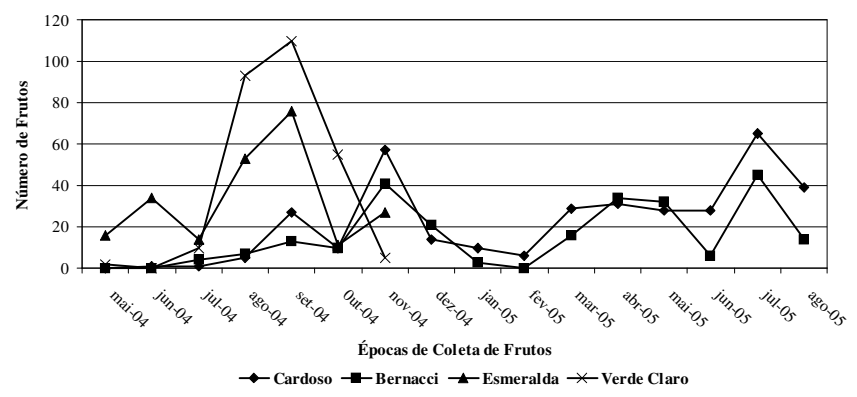

Figura 4. Efeito das diferentes épocas de avaliação no número médio de frutos das cultivares Cardoso, Bernacci, Esmeralda e Verde-Claro. Campinas, 2004/2005. 
A maior produção de frutos foi observada na cultivar Cardoso, seguida pela 'Bernacci' (Tabela 3). Embora nas cultivares Esmeralda e Verde-Claro tenha ocorrido número de frutos estatisticamente igual ao de 'Bernacci', suas produções foram inferiores à daquela. Segundo Torres et al. (2003), a biomassa fresca de cada fruto em condição de verão no Estado do Rio de Janeiro variou entre 40 e $50 \mathrm{~g}$. Nas condições do experimento, observou-se que as biomassas frescas médias por fruto das cultivares Bernacci, Esmeralda e Verde-Claro foram inferiores às relatadas por aqueles autores, ou seja, 38,8, 25,7 e 20,3g por fruto respectivamente (Figura 5). A biomassa fresca média de fruto da cultivar Cardoso foi de 51,4 g. A variação na biomassa fresca por fruto para cada cultivar foi elevada. Para 'Cardoso' a menor biomassa fresca obtida por fruto foi de $23,8 \mathrm{~g}$ e a maior de $100,3 \mathrm{~g}$. Para 'Bernacci', 'Esmeralda' e 'Verde-Claro', as menores e as maiores biomassas por fruto foram de 23,6 e $181,9 \mathrm{~g} ; 0,2$ e $38,9 \mathrm{~g}$ e 7,10 e $30,5 \mathrm{~g}$ respectivamente. Morgado e DiAS (1992), avaliando 43 genótipos de jiló da coleção de germoplasma da Embrapa Hortaliças, verificaram que a biomassa fresca média de cada fruto variou de 19 a $110 \mathrm{~g}$.

As cultivares comerciais proporcionaram resultados semelhantes, provavelmente por se tratar de genótipos melhorados desenvolvidos pelas empresas para as condições de clima e solo da Região Sudeste. As outras duas cultivares, possivelmente crioulas, foram objeto de estudo para verificar seu comportamento pela primeira vez nesta região. Entretanto, cabe ressaltar que as quatro cultivares têm origem na África Tropical.

Não houve diferença estatística entre as cultivares dentro de cada época de avaliação. Entretanto, deve-se ressaltar que as produções das cultivares Esmeralda e Verde-Claro se concentraram nos primeiros meses após o transplantio. Nas cultivares Cardoso e Bernacci foram observadas baixas produções nas primeiras avaliações, mas com frutos comerciais por um período mais longo.

\section{CONCLUSÕES}

1. As cultivares de jiló Esmeralda e Comprido Verde-Claro proporcionaram produções de frutos mais precoces em relação às cultivares Bernacci e Cardoso. Estas últimas produziram frutos por período mais prolongado.

2. O jiló 'Cardoso' foi o mais produtivo quanto ao número total de frutos e biomassa fresca total. 3 . As cultivares Bernacci e Cardoso, da coleção de jiló do IAC, constituem-se em genótipos com potencial para o melhoramento genético e para utilização no sistema de produção de subsistência ou na agricultura familiar, que são os sistemas tradicionais de cultivo de jiló.

\section{AGRADECIMENTOS}

Os autores agradecem ao Sr. Osvaldo Roberto Eicheuberger, funcionário do Centro de Horticultura do IAC e Severino Silva Nogueira, do Centro de Ecofisiologia e Biofísica pelo apoio na realização do trabalho. Agradecem, ainda, ao Dr. Armando Conagin pelo auxílio nas análises de intervalo de confiança.

\section{REFERÊNCIAS}

CARVALHO, A.C.P.P.; RIBEIRO, R.L.D. Análise da capacidade combinatória em cruzamentos dialélicos de três cultivares de jiloeiro. Horticultura Brasileira, Brasília, v.20, n.1, p.48-51, 2002.

FILGUEIRA, F.A.R. Novo manual de olericultura: agrotecnologia moderna na produção e comercialização de hortaliças. 2a . ed., rev., ampl.. Viçosa: UFV, 2003. 412p.

INSTITUTO MINEIRO DE AGROPECUÁRIA. Jiló (Solanum gilo). http://www.ima.mg.gov.br/vegetal/sementes/olerícolas/ jilo.pdf. Acesso em 23-9-2005. 1p.

MANGAN, F.; MOREIRA, M.; MARTUSCELLI, T. Produção e comercialização de sementes à população de falantes de português em Massachusets. University of Massachusets. Amherst. Disponível em: http://www.umassvegetable.org/ growers_services/pdf_files/portuguese_crops_ portuguese.pdf. Acesso em 13-2-2007.3p.

MINAMI, K.; GONÇALVES, A.L. Instruções práticas das principais hortaliças e condimentos. Piracicaba: Centro Acadêmico “Luiz de Queiróz”, 1986. 176p.

MORGADO, H.S.; DIAS, M.J.V. Caracterização da coleção de germoplasma de jiló no CNPH/Embrapa. Horticultura Brasileira, Brasília, v.10, n.2, p.86-88, 1992.

NAGAI, H. Jiló. Solanum gilo Radd. In: FAHL, J.I.; CAMARGO, M.B.P.; PIZZINATTO, M.A.; BETTI, J.A.; MELO, A.M.T.; DE MARIA, I.C.; FURLANI, A.M.C. Instruções agrícolas para as principais culturas econômicas. 6.ed., rev., atual. Campinas: IAC, 1998. 213 p. (Boletim, 200)

NERES, C.R.L.; VIEIRA, G.; DINIZ, E.R.; MOTA, W.F.; PUIATTI, M. Conservação do jiló em função da temperatura de armazenamento e do filme de polietileno de baixa densidade. Bragantia, Campinas, v.63, n.3, p.431-438, 2004.

ODETOLA, A.A.; IRANLOYE, Y.O.; AKINLOYE, O. Hypolipidaemic potentials of Solanum melongena and Solanum gilo on hypercholesterolemic rabbits. Pakistan Journal of Nutrition, v.3 n.3, p.180-187, 2004.

PICANÇO, M.; CASALI, V.W.D.; OLIVEIRA, I.V.R.; LEITE, G.L.D. Homópteros associados ao jiloeiro. Pesquisa Agropecuária Brasileira, Brasília, v.32, n.4, p.451-456, 1997. 
STEEL, R.G.D.; TORREI, J.H. Analysis of variance. IV: Splitplot designs and analysis. In: STEEL, R.G.D.; TORREI, J.H. (Eds). Principles and procedures of statistics. 2.ed. New York: Mc Graw Hill, 1980. p.377-400. (Capítulo, 16).

TORRES, J.L.R.; FABIAN, A.J.; POCAY, V.G. Níveis de adubação nitrogenada nas características morfológicas e produtividade do jiló. Horticultura Brasileira, Brasília, v. 21, n.2, p.166-169, 2003.

TRANI, P.E; MELO, A.M.T.; PASSOS, F.A.; TAVARES, M.; NAGAI, H.; SCIVITARRO, W.B. Berinjela, jiló, pimentahortícola e pimentão. In: RAIJ, B. van; CANTARELLA, H.; QUAGGIO, J.A.; FURLANI, A.M.C. (Ed.). Recomendações de adubação e calagem para o Estado de São Paulo. 2.ed. Campinas: Instituto Agronômico \& Fundação IAC, 1996. p.173.

WARD, J.H. Hierarchical grouping to optimize an objective function. Journal of the American Statistical Association, Alexandria, v.58, p.236-244, 1963.

WORLDCROPS. Jiló. Solanum gillo. Worldcrops for the Northeastern United State. Disponível em: http:// www.worldcrops.org/crops/JO:O.cfm. Acesso em: 23-9-2005. 